\title{
How do body-worn cameras affect the amount and makeup of police-initiated activities? A randomized controlled trial in Milwaukee, Wisconsin
}

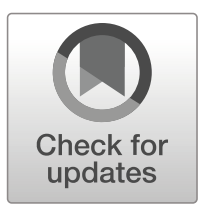

\author{
Daniel S. Lawrence $^{1}$ (D) Bryce E. Peterson ${ }^{1}$
}

Published online: 26 October 2019

(C) The Author(s) 2019

\section{Abstract}

Objectives Examine how the amount and makeup of police-initiated activities changed after the introduction of body-worn cameras (BWCs).

Methods From May 21 to November 22, 2016, patrol officers and sergeants from the Milwaukee Police Department were involved in a randomized controlled trial. Through a stratified random sampling procedure, half the officers $(n=252)$ were assigned BWCs, while officers from the control group $(n=252)$ continued business as usual. The counts of proactive activities, which included a total count of self-initiated events, as well as traffic stops, business checks, subject stops, and park and walks, were examined using random-effects negative binominal panel regression analyses. The models included a unique measure of contamination to assess its impact on officers' proactivity.

Results BWCs had no impact on the total amount of officer-initiated activities, traffic stops, or business checks. Officers with BWCs conducted approximately $8 \%$ fewer subject stops and $23 \%$ more park and walks than those in the control group. In all models, contamination levels were significantly, positively associated with the number of proactive activities that were conducted; however, the size of this effect was very small.

Conclusions Results suggest that BWC-wearing officers may be less likely to engage in proactive activities that are highly discretionary and that could potentially lead to confrontations with community members. As departments continue to develop BWC programs or fine-tune their existing BWC policies, more research is needed to understand the degree to which BWCs affect officers' behaviors and interactions with the public.

Keywords Body-worn cameras $\cdot$ BWC $\cdot$ Contamination $\cdot$ Police $\cdot$ Proactivity $\cdot$ Proactive $\cdot$ Self-initiated

Daniel S. Lawrence

dlawrence2@urban.org

1 Justice Policy Center, Urban Institute, 500 L'Enfant Plaza SW, Washington, DC 20024, USA 


\section{Introduction}

\section{Background and problem statement}

Given their rapid adoption by departments across the USA and abroad in recent years, body-worn cameras (BWCs) are increasingly becoming emblematic of modern policing. Recent national estimates indicate that $47.4 \%$ of all law enforcement agencies and $79.6 \%$ of agencies with 500 or more officers had acquired BWCs by 2016 (Hyland 2018). However, the expansion of BWC programs has not been without challenges. In particular, police officers and administrators have expressed concerns over the years about these tools reducing officer-initiated community contacts (i.e., "proactive policing" activities). In a survey conducted prior to the 2014 shooting of Michael Brown in Ferguson, MO, and the increased police scrutiny that resulted nationwide, officers reported that their colleagues would be less willing to conduct proactive policing activities if they were forced to wear BWCs (Jennings et al. 2014). Further, because BWC footage can be reviewed by police supervisors or outside entities (e.g., media or community groups), cameras may make officers less willing to engage in activities that could result in an increased chance of being disciplined, demoted, publically ridiculed, or injured (Shjarback et al. 2017; Wallace 2018).

Past BWC research has focused on how the cameras impact outcomes related to officer-community interactions, often measured by use of force incidents and citizen complaints, with fewer studies examining their impact on investigations and police organizations (Lum et al. 2019). Unfortunately, studies have generally not examined how BWCs affect officers' proactive activities, although this area of research has grown in recent years. In Lum et al.'s (2019) recent review of 70 publications on BWCs, only 7 specifically examined the impact of BWCs on self-initiated events. These seven studies focused on either the total number of proactive activities (Braga et al. 2018; Headley et al. 2017; Ready and Young 2015; Wallace et al. 2018; White et al. 2018), change in subject stops (Grossmith et al. 2015; Peterson et al. 2018; Ready and Young 2015), or traffic stops (Peterson et al. 2018).

The studies that examined how BWCs impact the total amount of proactive activities officers conduct are generally mixed. Using a difference-in-differences estimator of 416 officers from a randomized controlled trial (RCT) in Las Vegas, NV, Braga et al. (2018) found that BWCs were not associated with any statistically significant changes in officers' average monthly self-initiated call events. Similarly, White et al. (2018) examined how BWCs affected the total amount of self-initiated activities among 200 officers as part of a RCT in Tempe, AZ, and found no sizeable shifts in proactivity associated with BWC deployment. On the other hand, a study that involved 100 line officers at the Mesa, AZ, police department, half of whom were randomly assigned to receive a BWC during a 10-month study period from 2012 to 2013, found that BWCequipped officers conducted $13.5 \%$ more officer-initiated encounters than their nonBWC-equipped counterparts (Ready and Young 2015). Wallace et al. (2018) had similar findings from their RCT with 149 officers in the Spokane, WA, police department. They found that officers with BWCs had $8 \%$ greater odds of engaging in officerinitiated calls than the officers in the control group during the RCT period, which lasted approximately six months. Lastly, a small RCT with 51 officers in Hallandale Beach, FL, reported that BWC-equipped officers' proactive activities significantly increased 
from 12 to 21, on average, during the pre- and post-evaluation periods, respectively, but these activities did not change for control officers during the same time (Headley et al. 2017). In all, extant research has found either that BWCs have no impact on proactive activities or that cameras increase officer proactivity.

While these findings seem to contradict initial concerns that officers would pull back from this policing function if forced to wear BWCs, there has been less research examining specific types of proactive activities. It is possible that while the overall number of activities remains consistent or slightly increases after the deployment of cameras, the makeup of these activities changes. An earlier RCT in the greater metropolitan area of London with 2060 officers (814 in the treatment group) found that 3 of the 10 boroughs in the study had lower rates of stop and searches for officers with BWCs compared to their controls, but differences were only significant for one of the boroughs and nonsignificant when data were combined (Grossmith et al. 2015). As such, the authors concluded that there was no overall impact of BWCs on the number or type of stop and searches that were conducted. Ready and Young's (2015) RCT in Mesa, AZ, found that BWC-equipped officers conducted $9.8 \%$ fewer subject stops than their counterparts. An earlier analysis of the data used for the current study similarly found that Milwaukee police officers equipped with body cameras conducted $8 \%$ fewer subject stops between the pre- and post-intervention periods compared to control group officers (Peterson et al. 2018). In the same report, the authors found that BWCs did not significantly influence the amount of officer-initiated traffic stops.

The findings from extant literature on the topic demonstrate a significant gap in our understanding of how BWCs affect proactive activity. Of note, none of the studies reviewed above have examined whether the makeup of proactivity has changed among police officers, or offered an explanation as to why specific types of activities may increase or decrease after cameras are deployed. This is an area of research that Lum et al. (2019) recommended should be examined in future scholarly inquiries.

\section{The present study}

The current study aims to determine how BWCs impact officer-initiated community interactions through an RCT of the Milwaukee Police Department's (MPD) BWC program. While it is important to assess whether overall levels of proactivity change as a result of BWCs, officers are still expected to fill their time each day regardless of whether they have been equipped with a camera. Thus, this study also explores how the makeup of proactive activities change after officers were equipped with BWCs. For instance, we examine activities that involve greater exercises of power and discretion and have the potential to result in contentious police-community interactions, as well as activities that provide more opportunities for positive community interactions.

The data for this study contain information on all of the proactive activities by Milwaukee police officers between July 18, 2015, and November 22, 2016. The four most common categories of proactive activities during this period included traffic stops, business checks, subject stops, and park and walks. These accounted for $84.1 \%$ of all of the officers' proactive activities. Traffic stops are a well-known policing activity that occur when an officer pulls a vehicle over because of suspected traffic or vehicle violations. Business checks in Milwaukee involve officers entering a local business to either (a) check for proper licenses/permits or (b) speak with the owner and staff of a 
business about neighborhood concerns or activities. Subject stops include all officerinitiated stops of community members, such as when a person is behaving suspiciously or matches the description of a person suspected of criminal activities. These range from brief stops to obtain information from an individual to more involved detentions or stop and frisks that may lead to an arrest. Finally, park and walks primarily exist to promote community policing and involve officers parking their vehicles and walking around their assigned neighborhood to have a visible presence and to meet local community members.

Milwaukee is the largest city in Wisconsin, with a diverse population of nearly 599,000 in 2016, including $36 \%$ white residents, $38.8 \%$ black residents, and $18.2 \%$ Hispanic residents (U.S. Census Bureau 2016). The city has historically been plagued by high rates of crime. In 2016, Milwaukee's violent crime was 153.30 per 10,000 people, making it the 8 th most violent city with a population of 100,000 or more in the country, while its property crime rate $(406.40$ per 10,000$)$ ranked it in the top third of those cities (FBI 2017).

The department also faced significant challenges with police-community relations and a lack of public trust in the years prior to deploying BWCs, especially in neighborhoods with high rates of poverty and violent crime. For example, crime analyses by the authors found a disproportionate amount of crime happens in an area called the Center Street Corridor, which covers only $2.3 \%$ of the city but accounted for approximately $16 \%$ of the city's non-fatal victim shootings and homicides in 2015. Many city-wide initiatives have specifically focused to improve the challenges in this community, such as the more recent Public Safety Partnership and Project Safe Neighborhoods programs, which were launched in 2016 and 2017, respectively (Brackens and Steffick 2017; U.S. Attorney's Office 2019). Both efforts had a heavy focus on reducing gun violence and making areas safer through community partnerships.

Police-community relations were particularly tested in 2014 after the high-profile shooting of Dontre Hamilton by a MPD officer. Mr. Hamilton, who suffered from schizophrenia and paranoia, had fallen asleep on a park bench. A call for service was placed by a nearby business and the report from the responding officer stated that $\mathrm{Mr}$. Hamilton immediately became aggressive upon waking up, leading to the officer shooting Mr. Hamilton 14 times. The officer involved was fired but not charged with a crime, which sparked a series of protests across the city. Mr. Hamilton's death and the events that followed are considered the impetus for the department's BWC program. There was an outcry for MPD officers to be equipped with BWCs from community groups and city officials, including an online petition with more than 2000 signatures and several proposals from Milwaukee aldermen and the mayor.

Under this increased scrutiny and political pressure, the MPD developed a BWC policy and rollout plan in mid-2015. Between October 2015 and December 2016, the MPD equipped all patrol officers with the Axon Flex 2 BWC. These cameras are small devices that officers can mount on their head, collar, or shoulder and use to record an audio and a video of their interactions with community members. The cameras have a small buffering period that captures video of the $30 \mathrm{~s}$ immediately before the officer turns the camera on. No audio is captured during the buffering period.

The department's BWC policy requires officers to wear the cameras "at all times when on duty and performing or likely to perform enforcement duties" (MPD 2019, p. 4). The policy provides 12 specific examples when officers must activate their cameras 
when they arrive at the scene or begin investigative or enforcement activities. These include vehicle stops, impaired driver investigations, field interviews and pedestrian stops, transporting community members or prisoners, searches of persons or property, dispatched calls for service, crime scenes, crash scenes, advising a subject of Miranda warnings, suspect/witness statements and interviews, vehicle and foot pursuits, and emergency response to critical incidents. All officers at a scene with a BWC are required to activate their camera. Officers have the discretion to turn off or not activate their cameras for potentially sensitive events or circumstances, such as victims of a sexual assault, child victim statements, among others. The officers must make a verbal notation on the recording any time they plan to intentionally stop a recording prior to the completion of an event or incident. There were no changes to this policy during the current study period. Likewise, the MPD's stance on proactive activities did not change as a result of their BWC program and supervisors did not pressure officers to engage in more or less activities during this period.

The MPD partnered with researchers from the Urban Institute to develop a rigorous evaluation of the department's use of this technology. This partnership was supported by funding from the US Department of Justice through the Bureau of Justice Assistance's Strategies for Policing Innovation program.

\section{Methods}

\section{Randomized controlled trial procedures}

The MPD was tasked with deploying all its BWCs by the end of 2016. The department had nearly 2300 full-time sworn officers, which included approximately 1100 patrol officers who were prioritized to receive BWCs. This mandatory deployment took place over four phases, providing an opportunity for the evaluation team to conduct a RCT during this rollout. The first deployment of cameras occurred in October 2015 with 182 officers as part of a pilot program to assess best training practices for larger deployments. Phase 2 occurred in March 2016, during which we worked with the MPD to initiate a RCT where 252 officers were randomly assigned a BWC (the "treatment group") and 252 officers continued their work without BWCs (the "control group"). An additional 16 officers who were not part of the RCT were also given BWCs during the second deployment. The third phase occurred in June 2016 when 238 officers who were not part of the RCT were equipped with BWCs. The final deployment occurred across November and December 2016, when BWCs were distributed to the 252 control group officers and an additional 171 officers not involved in the RCT. Thus, the treatment group officers received their cameras around March 21, 2016, and the control group officers received their cameras beginning November 22, 2016, allowing for a 247-day intervention period (approximately 8 months).

As other studies on BWCs have noted, having officers volunteer into a research study can threaten external validity in that any findings may only be generalized to officers who volunteer (Ready and Young 2015; Young and Ready 2018). As implemented in this study, the officers assigned to receive a BWC were randomly, but also mandatorily, assigned a BWC. This methodology has proved successful in other largescale BWC evaluations (Braga et al. 2017; Owens et al. 2014; White et al. 2017). 
To facilitate the randomization, the MPD provided us with the department roster of all sworn personnel prioritized for BWCs a month prior to the second phase of BWC deployments. Officers who received a BWC as part of the department's pilot program, who were not patrol officers, and who were on any form of limited duty were considered ineligible for the RCT and removed from the roster. Officers from District 5 and the Neighborhood Task Force, who operate outside of district boundaries, received BWCs during the pilot deployment, leading to the majority of officers from those assignments to already have BWCs. As such, any remaining officers from these assignments were considered ineligible for the RCT since their working conditions were considerably different from the other districts where BWCs were not yet deployed. A total of 666 patrol officers and sergeants, from Districts 1, 2, 3, 4, 6, and 7, remained after filtering the roster on these criteria.

To randomly select the 504 officers who would be included in the study, we worked closely with the MPD to conduct a stratified random sampling procedure, where the strata included the officer's race (non-Hispanic white or nonwhite) and shift (power, late, day, or early). The sample of officers from each district was proportional to the size of that district relative to the overall department. For example, officers in District 1 represented $12 \%$ of the overall department; thus, officers from District 1 made up 12\% of the RCT sample. Once we knew the total sample per district based on these proportions, we were able to randomly select the appropriate number of officers from each district, and then randomly assign them by strata into the treatment and control groupings. The randomization was completed in SPSS.

\section{Group balance}

To determine the success of the randomization procedure, balance between the experimental groups on key officer characteristics was assessed with the effect-size statistics presented in Table 1. Imbalance would be exhibited by Cohen's $d$ in excess of 0.20 and a $t$ in excess of 1.96. The characteristics examined included the proportion of sergeants, females, race groups (white, black, Hispanic, and Asian), and the average tenure in the job. Furthermore, we examined the degree the experimental groups differed on proactivity during a pre-intervention period that matched the number of days of the study period (247 days, July 18, 2015 to March 20, 2016). These included the total number of proactive activities, business checks, traffic stops, subject stops, and park and walks. None of the tests found significant differences between the treatment and control groups across the officer characteristics or their pre-intervention proactive activities. As a result of these findings, we were confident that the random assignments of officers into the two experimental groupings were balanced in their composition.

\section{Data and analytic strategy}

The data for the current study come from administrative records and the MPD's proactivity database. The MPD requires officers to record the start and end times of all proactive activities using the computer-aided dispatch system on their in-car computers. There are many types of activities recorded in these data, but traffic stops $(43.7 \%)$, business checks $(25.2 \%)$, subject stops $(11.0 \%)$, and park and walks $(4.2 \%)$ were the top four proactive activities and made up $84.1 \%$ of all such activities during 
Table 1 Group balance diagnostics

\begin{tabular}{lllll}
\hline & $\begin{array}{l}\text { Control group } \\
\text { Mean (SD) }\end{array}$ & $\begin{array}{l}\text { Treatment group } \\
\text { Mean (SD) }\end{array}$ & $t$ & $d$ \\
\hline Sample characteristics & & & & \\
$n$ & 252 & 252 & & .068 \\
Sergeant & $15.5 \%$ & $13.1 \%$ & 0.76 & -.121 \\
Female & $10.3 \%$ & $14.3 \%$ & -1.36 & .000 \\
White & $62.3 \%$ & $62.3 \%$ & 0.00 & .091 \\
Black & $21.0 \%$ & $17.5 \%$ & 1.02 & .000 \\
Hispanic & $13.5 \%$ & $13.5 \%$ & 0.00 & -.165 \\
Asian & $3.2 \%$ & $6.7 \%$ & -1.85 & .064 \\
Tenure & $12.69(7.11)$ & $12.23(7.15)$ & 0.72 & .017 \\
Outcomes & & & & -.000 \\
All proactive activities & $312.37(253.12)$ & $308.23(230.62)$ & 0.19 & -.010 \\
Business checks & $80.81(109.34)$ & $80.82(96.00)$ & -0.00 & .049 \\
Traffic stops & $136.56(142.71)$ & $138.04(140.16)$ & -0.12 & .058 \\
Subject stops & $43.39(50.48)$ & $41.00(46.95)$ & 0.55 & 0.65 \\
Park and walks & $15.77(34.76)$ & $13.81(33.02)$ & & \\
\hline
\end{tabular}

Data correspond to pre-intervention period, July 18, 2015, to March 20, 2016

$S D$ standard deviation

the study period. The proactivity data were at the officer/event unit of analysis. That is to say, if three officers were involved in a single activity, then three cases were present in the data for that event, one for each officer. This data structure allowed us to calculate the total count of proactive activities for each officer and identify which officers were present at the event.

The BWC intervention study period occurred across 247 days (approximately 8 months) from March 21, 2016, to November 22, 2016. We used an equal period of time for the pre-intervention period, which lasted from July 18, 2015, to March 20, 2016. We used panel data to better measure change across time, where the data were aggregated into sixteen 31-day periods, creating eight pre- and post-intervention periods across the two experimental groups. The first and last panels included 30 days.

It is worth noting that the majority of patrol officers' time in each shift is spent responding to calls for service from community members and helping to investigate crimes. For that reason, officers typically have a limited amount of time in their workday to engage in proactive activities; however, analysis of the officers' activities shows that a large proportion of their time is spent conducting proactive activities. In the pre-intervention time period, the group mean of the officers' on-call events was $38.0 \%$ (SD = 19.1) proactive activities. However, the amount of time officers spent at these events was much lower, corresponding to $20.6 \%$ (SD $=14.3$ ) of their time on all activities. Thus, these officers conducted many proactive activities during their work day, but spent less time on these activities compared to calls for service.

Table 2 displays the descriptive statistics of the outcomes across the 31-day panels for the full study period, both the pre- and post-intervention periods, and the paired- 


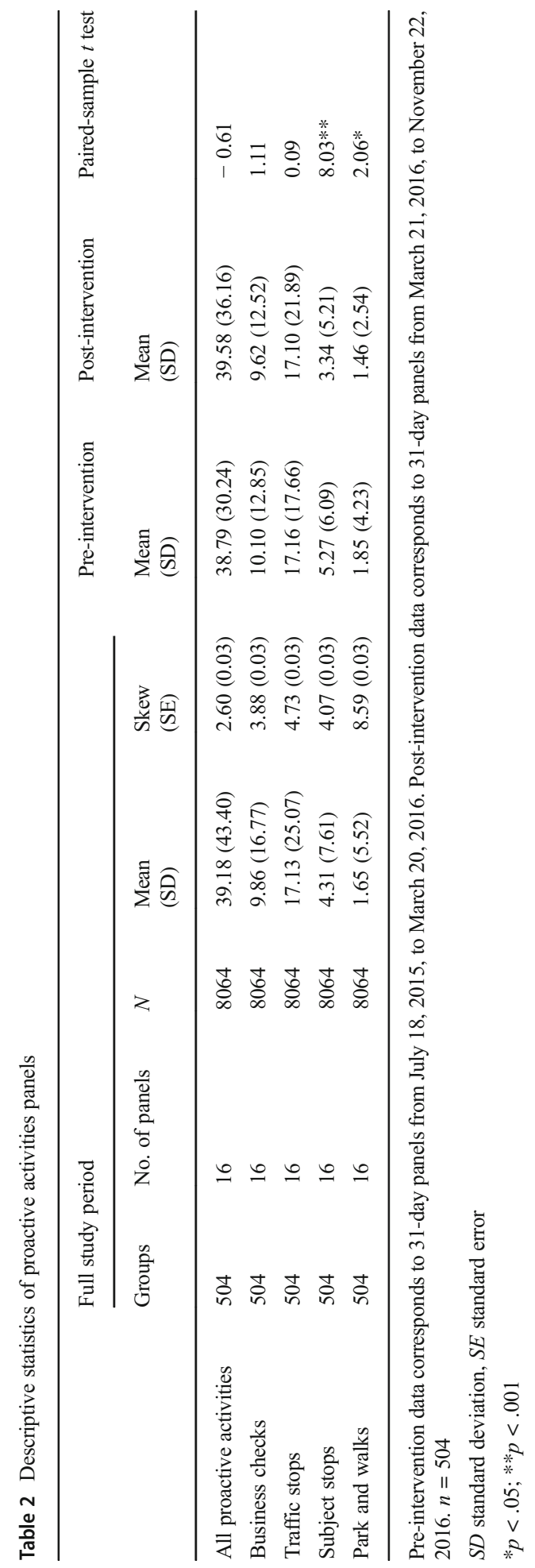


sample $t$-statistics to assess the change of the outcomes for the RCT officers. Results indicate that the average amount of both subject stops and park and walks significantly declined during this time, but the other activities were not significantly different.

Because all of the outcomes are count measures with evidence of skewness and overdispersion, we used random-effects negative binomial panel regression models to prevent biased estimates that could result from ordinary least squares regressions (Hilbe 2011; Long and Freese 2006; MacDonald and Lattimore 2010). We used the NBVARGR command and post-estimation statistics in Stata 15.1 to assess whether the Poisson or negative binominal distributions were more appropriate for these data. Negative binomial regression models, as compared to Poisson models, take into account unobserved heterogeneity among observations and do not have downwardbiased standard errors. The negative binominal models were superior with all outcomes.

We used difference-in-differences (DiD) to estimate the difference between the treatment officers' pre-intervention and post-intervention outcomes, relative to the same difference for the control officers in the experiment. To estimate the $\mathrm{DiD}$, we included the following independent variables in our models: group, a dummy variable identifying whether an individual officer was in the treatment group (1) or control group (0); period, an indicator of whether each panel was during the intervention (1) or preintervention period (0); and the product of the group dummy with the period dummy, which provided the DiD estimate of the effect of BWCs on the outcome. We also controlled for a number of covariates in the model, including whether the officers were a sergeant (yes $=1$, no $=0$ ), their sex (female $=1$ ), dummy coded race variables (black, Hispanic, or other race) with white as the reference category, and the officers' tenure as a MPD officer in years. These characteristics were measured on the date the RCT began.

The examined outcomes include the total count of all proactive activities, as well as the individual counts of traffic stops, business checks, subject stops, and park and walks. To better account for the rate of these events relative to officers' time in the field, we included the total number of proactive activities as an exposure variable in the models examining the changes in traffic stops, business checks, subject stops, and park and walks. A critical assumption of DiD estimation is that the two experimental groups have similar pre-intervention trends in the selected outcome variables (i.e., the parallel trends assumption; see Bertrand et al. 2004). We examined trend lines for the eight preintervention periods for each outcome to assess this assumption and found that trend lines for the treatment group were clearly equal to the trend lines for the control group (i.e., the lines were overlapping entirely during the pre-intervention periods).

We used the XTNBREG command to provide incidence rate ratios of the $\mathrm{DiD}$ estimator described above and the covariates used in the models. By using the incidence rate ratio, we can more intuitively determine the percentage change of the outcome between the pre- and post-intervention periods on average (Piza 2012). For example, an incidence rate ratio for the DiD estimator of 1.04 would indicate that the treatment group's count of the outcome increased by $4 \%$ on average during the postintervention period compared to the control group, while a ratio of 0.87 would indicate that the treatment group's count of the outcome decreased by $13 \%$ on average compared to the control group. Incidence rate ratios with continuous covariates are interpreted as a change in the outcome on average by the percentage with every one- 
unit increase of the covariate. For example, a 1.12 incidence rate ratio for the covariate measuring tenure (measured in years) would suggest that the outcome increased by approximately $12 \%$ on average with every additional year of tenure.

We tested three models for each outcome. The first, model A, was an unconditional regression that only included the variables for the DiD. This model allowed us to assess the change in the outcomes from the RCT with no other controls. Model B built on model A by adding BWC-contamination levels, a description of which is detailed in the next section. Finally, model $\mathrm{C}$ includes all other covariates described above. For each model, we report the incident rate ratios and $95 \%$ confidence intervals for each independent variable, the model's Wald Chi-square estimate, and the Akaike information criterion and Bayesian information criterion to assess and compare model fit.

\section{Contamination}

Since the adoption of BWCs into the policing field, there have been many scholarly discussions about the problem of contamination in experimental evaluations. In particular, contamination threatens internal validity when officers who are and are not equipped with a BWC are involved in the same policing event. The randomization occurs at the individual unit of analysis, but policing activities occur at the event unit of analysis, often times with multiple officers, potentially leading to high contamination when analyzing outcomes at the event level. As Braga et al. (2017) has advised, contaminated control conditions can undermine the counterfactual contrast between officers that receive the treatment and officers that do not. Ariel et al. (2018) dive deep into this issue and go as far to say that BWC studies that are randomized by individual render experimental results misleading.

One approach in prior research to respond to this issue has been to randomize officers by shift, where all officers on a randomly chosen shift are equipped with a BWC during that shift while officers do not wear cameras during control shifts (see Ariel et al. 2015, 2016a, b; Farrar and Ariel 2013). However, this approach still yields intra-officer contamination in that the same officers would wear BWCs on one shift and leave them off on other shifts. This design also produces additional threats to internal validity as the study participants become aware of the intervention. For example, what is known as the compensatory rivalry social threat to validity could occur when officers increase their efforts to perform well in comparison to the treatment group (Horner et al. 2006). In this context, officers could alter their behaviors purposely when they don't have a BWC to match their behaviors when they do. Another approach that reduces the compensatory rivalry social threat to validity is to randomize entire districts, where all officers within a randomly selected district are permanently assigned BWCs (Hedberg et al. 2016; Katz et al. 2014, 2015; Morrow et al. 2016).

The concerns raised about contamination for RCTs that randomize officers-as opposed to shifts or districts - are valid, but little research has estimated the extent contamination actually has on measured outcomes. The current study seeks to address this research gap by including a measure of contamination in our models. Using the officer-level identifiers in MPD's proactive activity data, we were able to identify the proportion of officers with and without BWCs at each event. We also recognize that there were officers outside of the two experimental groups both with and without 
BWCs (e.g., officers who received cameras in the phase 1 and 3 deployments and officers not selected to be in the RCT sample during the phase 2 deployment). As such, we define contamination as present in an event when (1) a control group officer was with any BWC-wearing officers at the scene and where (2) a treatment group officer was at the scene with any officer not wearing a BWC.

Figure 1 details the trend lines of contamination levels during proactive activities for officers involved in the RCT. The events were separated into three mutually exclusive categories: events where control group officers were involved, events where treatment group officers were involved, and events where both control and treatment group officers were involved. Prior to the RCT, contamination levels for these officerswhich include events where the non-BWC-equipped RCT officers interacted with one or more BWC-wearing officers from the phase 1 deployment-were relatively low, averaging at 5.15\% from October 2015 to February 2016. Contamination increased greatly during the RCT study period. Overall, contamination levels for these officers averaged 34.4\% from March to November 2016, but levels varied across the different types of events. As expected, contamination levels were at or near $100 \%$ for events where both the treatment and control group officers were involved. Treatment group officers had higher contamination levels than control group officers prior to the phase 3 BWC deployment that occurred in June 2016. This is because only $40.4 \%$ of the department had BWCs before that deployment, resulting in treatment group officers interacting with more officers that did not have BWCs in the daily activities. After the phase 3 deployment, $61.9 \%$ of MPD patrol officers were equipped with BWCs, causing this pattern to switch to where contamination levels decreased for the treatment group officers (as more MPD officers had BWCs) and increased for control group officers. After the 4th deployment in November and December 2016, nearing all officers had BWCs and contamination levels dropped significantly. In January 2017 (a month after the end of the RCT study period), the MPD removed BWCs from all sergeants, resulting in stable, low levels of contamination from January 2017 onward.

We examined contamination levels across proactive activities further by separating out the five distinct activities for all officers involved in the RCT, displayed in Fig. 2.

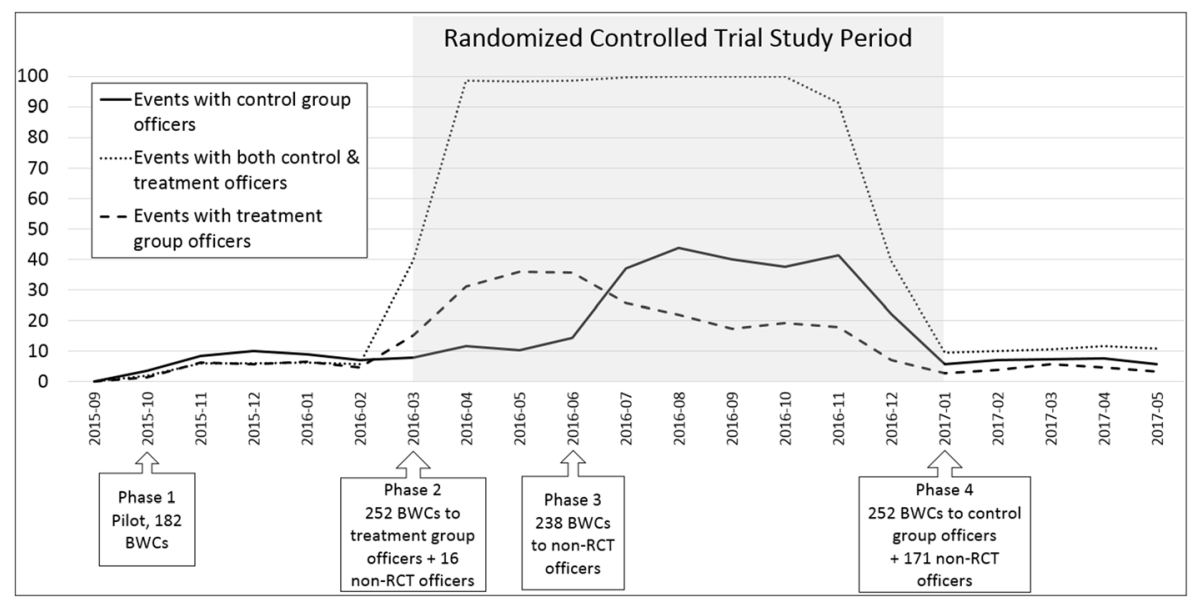

Fig. 1 Contamination levels for proactive activity events involving RCT officers 


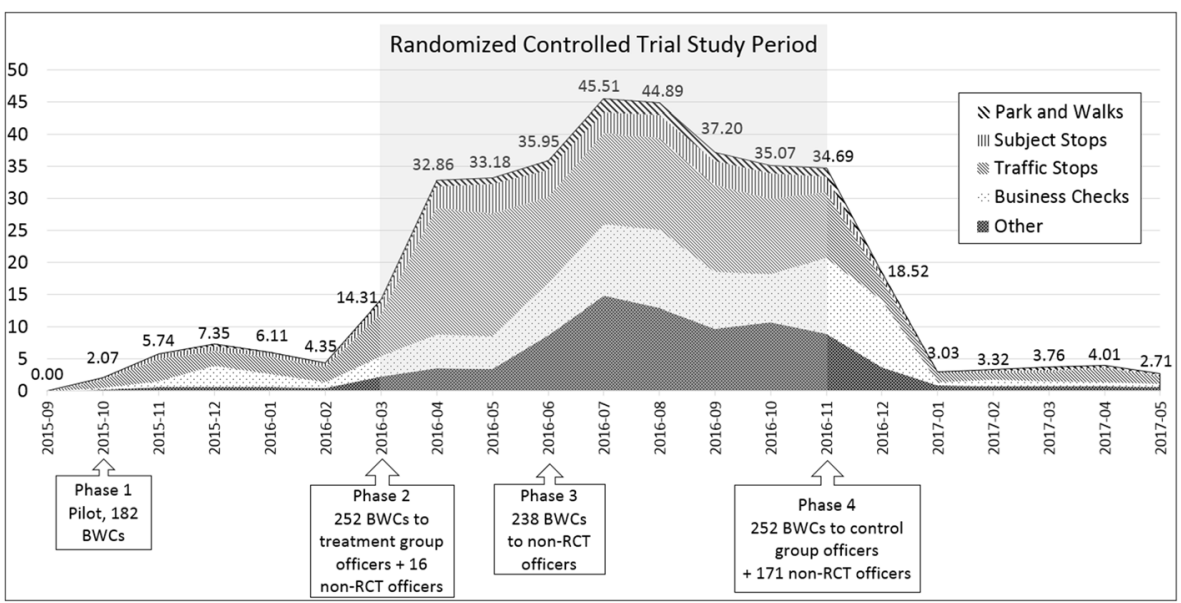

Fig. 2 Proactive activity contamination levels, by type, among RCT officers

Peak levels of contamination for the RCT officers occurred in July 2016, the month after the third phase of BWC deployments. During this month, $45.5 \%$ of all events were contaminated. Traffic stops accounted for the greatest amount of these contamination levels, ranging from 29.7 to $60.1 \%$ of the overall contamination during the RCT study period. This is perhaps not surprising considering that officers often request backup during these types of stops. On the other hand, subject stops only accounted for 7.0 to $13.6 \%$ of the total contamination during the RCT. This might be a result of officers not requesting backup during relatively brief encounters with individuals in the street. Park and walks consistently had the lowest levels of contamination, accounting for just 2.9 to $4.8 \%$ of the overall contamination during the RCT. This is likely because officers typically perform this activity by themselves and do not require backup.

As our analyses relied on panel regression models, we calculated the degree of officerlevel-contaminated events for each outcome in each period. For example, in the business checks analyses, we calculated the percent contamination for each officer as the number of business checks with contamination divided by the total number of business checks within the specific panel period. This provided a more accurate measure specific to the examined outcome as opposed to calculating a general contamination level for each officer. It is worth emphasizing that this study does not examine how a mixture of officers with or without a BWC during a proactive activity affected the outcome of that encounter, but instead, examines whether the degree of monthly events with contamination influenced the amount of proactive activities individual officers conducted.

\section{Results}

\section{Proactive activities}

We first examined the impact BWCs had on the officers' total amount of proactive activities, presented in Table 3. The results of each model indicated that BWC-equipped officers increased their proactive activities by a factor of 1.02 to 1.03 , or approximately 2 to $3 \%$, 
Table 3 BWC impact on proactive activities

\begin{tabular}{|c|c|c|c|c|c|c|}
\hline & \multicolumn{2}{|l|}{ Model A } & \multicolumn{2}{|l|}{ Model B } & \multicolumn{2}{|l|}{ Model C } \\
\hline & IRR & $95 \% \mathrm{CI}$ & IRR & $95 \% \mathrm{CI}$ & IRR & $95 \% \mathrm{CI}$ \\
\hline BWC group & $0.93^{\mathrm{t}}$ & $0.86 \mid 1.00$ & 0.95 & $0.88 \mid 1.02$ & 0.94 & $0.88 \mid 1.01$ \\
\hline Period & $0.91 * *$ & $0.87 \mid 0.95$ & $0.75 * *$ & $0.71 \mid 0.79$ & $0.75^{* *}$ & $0.71 \mid 0.79$ \\
\hline Group $\times$ period & 1.02 & $0.96 \mid 1.08$ & 1.03 & $0.97 \mid 1.10$ & 1.03 & $0.97 \mid 1.10$ \\
\hline Contamination & & & $1.00 * *$ & $1.00 \mid 1.01$ & $1.00 * *$ & $1.00 \mid 1.01$ \\
\hline Sergeant & & & & & $0.53 * *$ & $0.47 \mid 0.60$ \\
\hline Female & & & & & $0.87 *$ & $0.79 \mid 0.96$ \\
\hline Black (vs. white) & & & & & 0.98 & $0.91 \mid 1.07$ \\
\hline Hispanic (vs. white) & & & & & 1.00 & $0.91 \mid 1.10$ \\
\hline Other race (vs. white) & & & & & $0.74 * *$ & $0.63 \mid 0.86$ \\
\hline Tenure & & & & & $0.98 * *$ & $0.98 \mid 0.98$ \\
\hline Constant & $1.89 * *$ & $1.79 \mid 2.00$ & $1.85^{* *}$ & $1.76 \mid 1.96$ & $2.56^{* *}$ & $2.37 \mid 2.77$ \\
\hline Wald $\mathrm{Chi}^{2}$ & $33.16^{* *}$ & & $229.53 * *$ & & $466.09 * *$ & \\
\hline AIC & $70,518.44$ & & $70,321.11$ & & $70,122.94$ & \\
\hline $\mathrm{BIC}$ & $70,560.41$ & & $70,370.08$ & & $70,213.88$ & \\
\hline
\end{tabular}

Random-effects negative binominal panel regressions; $N=504$ across 16 panels, control group $n=252$, treatment group $n=252$

$I R R$ incident rate ratio, $S E$ standard error

${ }^{\mathrm{t}} p<.10 ; * p<.01 ; * * p<.001$

compared to officers from the control group; although these difference were not significant. Therefore, BWCs had no impact on the total amount of officer-initiated activities.

Other notable, significant findings included that as the average contamination levels increased, so did their total amount of proactive activities; however, the size of this change was very small: proactive activities increased by approximately $0.45 \%$ on average when contamination levels increased by $1 \%(p<.001)$. Not surprisingly, sergeants recorded approximately $47 \%$ fewer total proactive activities on average than patrol officers $(p<.001)$, but this is likely a result of their responsibilities in the field. Female officers were observed with $13 \%$ fewer activities on average than males ( $p=$ .007 ), and officers with racial backgrounds other than black and Hispanic were found to have $26 \%$ fewer activities than white officers $(p<.001)$. Officers further into their careers had significantly fewer proactive activities, with an approximately $2 \%$ decrease in activities on average for each additional year of tenure $(p<.001)$.

\section{Traffic stops}

While the count of total proactive activities did not significantly change as a result of the BWCs, we were interested in examining the makeup of these activities to assess if officers actively pursued different types of proactive activities after being equipped with a BWC. We first examined this relation between BWCs and traffic stops (Table 4). The DiD results from the unconditional model (model A) noted a marginally significant 
Table 4 BWC impact on traffic stops

\begin{tabular}{|c|c|c|c|c|c|c|}
\hline & \multicolumn{2}{|l|}{ Model A } & \multicolumn{2}{|l|}{ Model B } & \multicolumn{2}{|l|}{ Model C } \\
\hline & IRR & $95 \% \mathrm{CI}$ & IRR & $95 \% \mathrm{CI}$ & IRR & $95 \% \mathrm{CI}$ \\
\hline BWC group & 0.97 & $0.90 \mid 1.05$ & 0.99 & $0.92 \mid 1.07$ & 1.01 & $0.93 \mid 1.10$ \\
\hline Period & $0.96^{*}$ & $0.93 \mid 1.00$ & $0.88^{* *}$ & $0.84 \mid 0.92$ & $0.89 * *$ & $0.85 \mid 0.93$ \\
\hline Group $\times$ period & $0.96^{\mathrm{t}}$ & $0.91 \mid 1.01$ & 0.97 & $0.92 \mid 1.02$ & 0.99 & $0.94 \mid 1.05$ \\
\hline Contamination & & & $1.00 * *$ & $1.00 \mid 1.00$ & $1.00 * *$ & $1.00 \mid 1.00$ \\
\hline Sergeant & & & & & $1.35 * *$ & $1.15 \mid 1.58$ \\
\hline Female & & & & & $0.72 * *$ & $0.64 \mid 0.81$ \\
\hline Black (vs. white) & & & & & $0.89^{*}$ & $0.80 \mid 0.99$ \\
\hline Hispanic (vs. white) & & & & & $1.39 * *$ & $1.23 \mid 1.57$ \\
\hline Other race (vs. white) & & & & & $1.18^{t}$ & $0.98 \mid 1.43$ \\
\hline Tenure & & & & & $1.04 * *$ & $1.03 \mid 1.04$ \\
\hline Constant & $0.09 * *$ & $0.09 \mid 0.10$ & $0.09 * *$ & $0.09 \mid 0.10$ & $0.06^{* *}$ & $0.06 \mid 0.07$ \\
\hline Wald $\mathrm{Chi}^{2}$ & $25.48 * *$ & & $72.44 * *$ & & $282.62 * *$ & \\
\hline AIC & $51,347.26$ & & $51,301.20$ & & $51,071.34$ & \\
\hline $\mathrm{BIC}$ & $51,389.23$ & & $51,350.17$ & & $51,162.28$ & \\
\hline
\end{tabular}

Random-effects negative binominal panel regressions with count of proactive activities as exposure variable; $N=504$ across 16 panels, control group $n=252$, treatment group $n=252$

$I R R$ incident rate ratio, $C I$ confidence interval

${ }^{\mathrm{t}} p<.10 ; * p<.05 ; * * p<.001$

$4 \%$ decrease, on average, in the amount of traffic stops conducted by treatment group officers compared to officers from the control group $(p=.098)$. But this relationship became nonsignificant as other covariates were added to the model. Thus, we found that BWCs had no impact on officers' traffic stops.

All additional control variables in models $\mathrm{B}$ and $\mathrm{C}$ were found to significantly relate to the number of traffic stops officers initiated. Similar to the results on proactive activities, we found that as the average contamination levels increased, so did the amount of traffic stops, but again, the size of this change was very small. Most notable from these findings was that female officers conducted $28 \%$ fewer traffic stops on average compared to males $(p<.001)$; sergeants conducted $35 \%$ more traffic stops on average compared to patrol officers $(p<.001)$. This may be because sergeants are often called to traffic stop scenes to provide supervisory support to the patrol officer who initiated the stop. Finally, Hispanic officers conducted $39 \%$ more traffic stops on average compared to white officers $(p<.001)$.

\section{Business checks}

Table 5 indicates that BWCs did not affect how many business checks officers initiated during the RCT study period as the DiD estimators were not significant across all three models. Again, contamination appears to slightly increase business checks $(p<.001)$, but the effect size is quite small. Further, Hispanic officers conducted $60 \%$ more 
Table 5 BWC impact on business checks

\begin{tabular}{|c|c|c|c|c|c|c|}
\hline & \multicolumn{2}{|l|}{ Model A } & \multicolumn{2}{|l|}{ Model B } & \multicolumn{2}{|l|}{ Model C } \\
\hline & IRR & $95 \% \mathrm{CI}$ & IRR & $95 \% \mathrm{CI}$ & IRR & $95 \% \mathrm{CI}$ \\
\hline BWC group & 0.98 & $0.89 \mid 1.08$ & 0.96 & $0.87 \mid 1.06$ & 0.98 & $0.89 \mid 1.08$ \\
\hline Period & 0.99 & $0.95 \mid 1.03$ & $0.88 * * *$ & $0.84 \mid 0.92$ & $0.88 * * *$ & $0.84 \mid 0.92$ \\
\hline Group $\times$ period & 1.03 & $0.97 \mid 1.09$ & 1.03 & $0.97 \mid 1.09$ & 1.01 & $0.96 \mid 1.07$ \\
\hline Contamination & & & $1.00 * * *$ & $1.00 \mid 1.00$ & $1.00 * * *$ & $1.00 \mid 1.00$ \\
\hline Sergeant & & & & & $0.78 * *$ & $0.65 \mid 0.93$ \\
\hline Female & & & & & 1.06 & $0.93 \mid 1.22$ \\
\hline Black (vs. white) & & & & & 1.04 & $0.93 \mid 1.18$ \\
\hline Hispanic (vs. white) & & & & & $1.60 * * *$ & $1.38 \mid 1.84$ \\
\hline Other race (vs. white) & & & & & $0.81^{*}$ & $0.66 \mid 1.00$ \\
\hline Tenure & & & & & $1.02 * * *$ & $1.01 \mid 1.02$ \\
\hline Constant & $0.09^{* * *}$ & $0.08 \mid 0.10$ & $0.09 * * *$ & $0.08 \mid 0.10$ & $0.07 * * *$ & $0.06 \mid 1.08$ \\
\hline Wald $\mathrm{Chi}^{2}$ & 1.15 & & $118.48 * * *$ & & $195.59 * * *$ & \\
\hline $\mathrm{AIC}$ & $40,074.92$ & & $39,963.03$ & & $39,896.92$ & \\
\hline $\mathrm{BIC}$ & $40,116.89$ & & $40,011.99$ & & $39,987.86$ & \\
\hline
\end{tabular}

Random-effects negative binominal panel regressions with count of proactive activities as exposure variable; $N=504$ across 16 panels, control group $n=252$, treatment group $n=252$

$I R R$ incident rate ratio, $C I$ confidence interval

$* p<.05 ; * * p<.01 ; * * * p<.001$

business checks on average than white officers $(p<.001)$, sergeants had $22 \%$ fewer business checks on average than patrol officers $(p=.007)$, and each year of additional tenure resulted a $2 \%$ increase in business checks among officers $(p<.001)$.

\section{Subject stops}

The results of each model in Table 6 indicate that BWC-equipped officers had fewer subject stops by a factor of 7 to $8 \%$ on average compared to officers from the control group (model A: $p=.039$; model $\mathrm{B}: p=.020$; model $\mathrm{C}: p=.024$ ). As was the case in the other analyses, contamination levels had a small, but significantly positive, relationship with the number of subject stops. With each unit increase in contamination, subject stops increased by $0.50 \%$ on average $(p<.001)$. Sergeants were involved in $106 \%$ more subject stops than their patrol officer counterparts $(p<.001)$. As was the case for traffic stops, this is likely because sergeants often backup patrol officers in the field when they initiate a subject stop to provide supervisory support and guidance. Thus, while sergeants may not always be the ones initiating subject stops, they are more likely on average than regular officers to be on the scene of a subject stop initiated by another officer. Females and black officers had 13\% $(p=.056)$ and $27 \%(p<.001)$ fewer subject stops on average, respectively, while officers who were Hispanic conducted $15 \%$ more subject stops than their white counterparts $(p=.067)$. Finally, a $2 \%$ increase of subject stops was observed for each additional year of tenure $(p<.001)$. 
Table 6 BWC impact on subject stops

\begin{tabular}{|c|c|c|c|c|c|c|}
\hline & \multicolumn{2}{|l|}{ Model A } & \multicolumn{2}{|l|}{ Model B } & \multicolumn{2}{|l|}{ Model C } \\
\hline & IRR & $95 \% \mathrm{CI}$ & IRR & $95 \% \mathrm{CI}$ & IRR & $95 \% \mathrm{CI}$ \\
\hline BWC group & 0.97 & $0.88 \mid 1.08$ & 0.98 & $0.88 \mid 1.08$ & 0.98 & $0.88 \mid 1.08$ \\
\hline Period & $0.61 * *$ & $0.58 \mid 0.64$ & $0.49 * *$ & $0.46 \mid 0.52$ & $0.49 * *$ & $0.46 \mid 0.52$ \\
\hline Group $\times$ period & $0.93 *$ & $0.86 \mid 1.00$ & $0.92 *$ & $0.85 \mid 0.99$ & $0.92 *$ & $0.85 \mid 0.99$ \\
\hline Contamination & & & $1.00 * *$ & $1.00 \mid 1.01$ & $1.00 * *$ & $1.00 \mid 1.01$ \\
\hline Sergeant & & & & & $2.06 * *$ & $1.73 \mid 2.46$ \\
\hline Female & & & & & $0.87^{\mathrm{t}}$ & $0.75 \mid 1.00$ \\
\hline Black (vs. white) & & & & & $0.73 * *$ & $0.65 \mid 0.83$ \\
\hline Hispanic (vs. white) & & & & & $1.15^{\mathrm{t}}$ & $0.99 \mid 1.33$ \\
\hline Other race (vs. white) & & & & & 1.06 & $0.85 \mid 1.33$ \\
\hline Tenure & & & & & $1.02 * *$ & $1.01 \mid 1.02$ \\
\hline Constant & $0.10^{* *}$ & $0.09 \mid 0.11$ & $0.09 * *$ & $0.09 \mid 0.10$ & $0.08 * *$ & $0.07 \mid 0.09$ \\
\hline Wald Chi ${ }^{2}$ & $831.89 * *$ & & $1001.19 * *$ & & $1138.21 * *$ & \\
\hline AIC & $32,785.87$ & & $32,568.84$ & & $32,430.81$ & \\
\hline $\mathrm{BIC}$ & $32,827.84$ & & $32,617.80$ & & $32,521.75$ & \\
\hline
\end{tabular}

Random-effects negative binominal panel regressions with count of proactive activities as exposure variable; $N=504$ across 16 panels, control group $n=252$, treatment group $n=252$

$I R R$ incident rate ratio, $C I$ confidence interval

${ }^{\mathrm{t}} p<.10 ; * p<.05 ; * * p<.001$

\section{Park and walks}

The final proactive activity examined was park and walks. Results, presented in Table 7 , indicate that officers equipped with BWCs conducted 22 to $23 \%$ more park and walks on average than control group officers. It is worth noting that this was a relatively rare activity for officers, who averaged only 1.65 park and walks per period across the duration of the study, which may explain the large percentage changes (model A: $p=$ .003 ; model B: $p=.003$; model $\mathrm{C}: p=.005$ ).

The results in model $\mathrm{C}$ indicate a $1.06 \%$ increase in park and walks on average when contamination levels increased by $1 \%(p<.001)$. Sergeants and Hispanic officers had $72 \%$ $(p<.001)$ and $28 \%(p=.008)$ more park and walks than their counterparts, respectively, while officers with racial backgrounds other than black and Hispanic conducted $37 \%$ fewer park and walks than white officers $(p=.001)$. Finally, a $2 \%$ increase in subject stops was observed for each additional year of tenure $(p<.001)$.

\section{Discussion and policy implications}

The goals of this study were to better understand how BWCs may influence the total amount of officer-initiated proactive activities and whether the makeup of those 
Table 7 BWC impact on park and walks

\begin{tabular}{|c|c|c|c|c|c|c|}
\hline & \multicolumn{2}{|l|}{ Model A } & \multicolumn{2}{|l|}{ Model B } & \multicolumn{2}{|l|}{ Model C } \\
\hline & IRR & $95 \% \mathrm{CI}$ & IRR & $95 \% \mathrm{CI}$ & IRR & $95 \% \mathrm{CI}$ \\
\hline BWC group & 1.00 & $0.87 \mid 1.16$ & 1.00 & $0.87 \mid 1.16$ & 1.04 & $0.90 \mid 1.20$ \\
\hline Period & 1.05 & $0.95 \mid 1.16$ & $0.75^{* *}$ & $0.68 \mid 0.84$ & $0.75^{* *}$ & $0.68 \mid 0.84$ \\
\hline Group $\times$ period & $1.23 *$ & $1.07 \mid 1.41$ & $1.23 *$ & $1.07 \mid 1.41$ & $1.22 *$ & $1.06 \mid 1.40$ \\
\hline Contamination & & & $1.01^{* *}$ & $1.01 \mid 1.01$ & $1.01 * *$ & $1.01 \mid 1.01$ \\
\hline Sergeant & & & & & $1.72 * *$ & $1.30 \mid 2.28$ \\
\hline Female & & & & & 0.89 & $0.75 \mid 1.06$ \\
\hline Black (vs. white) & & & & & 1.11 & $0.95 \mid 1.30$ \\
\hline Hispanic (vs. white) & & & & & $1.28^{*}$ & $1.07 \mid 1.55$ \\
\hline Other race (vs. white) & & & & & $0.63^{*}$ & $0.47 \mid 0.84$ \\
\hline Tenure & & & & & $1.02 * *$ & $1.01 \mid 1.03$ \\
\hline Constant & $0.01 * *$ & $0.01 \mid 0.01$ & $0.01 * *$ & $0.01 \mid 0.01$ & $0.01 * *$ & $0.01 \mid 0.01$ \\
\hline Wald $\mathrm{Chi}^{2}$ & $31.13 * *$ & & $434.20 * *$ & & $495.69 * *$ & \\
\hline AIC & $19,421.61$ & & $19,070.79$ & & $19,019.52$ & \\
\hline BIC & $19,463.58$ & & $19,119.75$ & & $19,110.46$ & \\
\hline
\end{tabular}

Random-effects negative binominal panel regressions with count of proactive activities as exposure variable; $N=504$ across 16 panels, control group $n=252$, treatment group $n=252$

$I R R$ incident rate ratio, $C I$ confidence interval

${ }^{\mathrm{t}} p<.10 ; * p<.01 ; * * p<.001$

activities changed after officers were equipped with a BWC. We also examined the impact of study contamination on officers' proactive behaviors. Our analyses revealed several key findings that warrant further discussion.

First, we found that officers assigned to control group conditions decreased their monthly number of activities from 39.05 to 38.24 , on average, between the preintervention and post-intervention study periods. Conversely, officers equipped with BWCs increase their average activities per month from 38.53 to 40.91 across the same two periods. However, these changes were not significant in our DiD models, indicating that BWCs may not meaningfully impact how often an officer engages in a proactive activity. This finding is not surprising given that these activities are not a complete measure of officers' core duties. As previously described, proactive activities accounted for $21 \%$ of the officers' time in the field during the pre-intervention time period, and this did not change after camera deployment. Regardless of whether they were equipped with a BWC, Milwaukee officers continued to respond to calls for service and investigate crimes, while performing self-initiated work when they were able.

Although the overall number of proactive activities did not significantly vary between the two experimental groups, it is important to understand whether BWCwearing officers spend the time they have available for self-initiated work pursuing different types of proactive activities than officers not equipped with cameras. This was the second major focus area of the current study. We examined how the makeup of the 
four most frequently occurring proactive activities (traffic stops, business checks, subject stops, and park and walks), which accounted for $84.1 \%$ of all self-initiated work, changed as a result of BWCs.

We found that officers equipped with a BWC are more selective in the proactive activities they perform during their patrol activities. Specifically, officers with BWCs had roughly $8 \%$ fewer subject stops on average in the 8-month postintervention study period, but conducted $23 \%$ more park and walks, than control group officers. This suggests that BWC-wearing officers may have been less likely to engage proactive activities that were highly discretionary and could potentially lead to confrontations with community members. For example, subject stops often involve an officer detaining a community member for questioning who appears to be acting suspiciously or who may fit the description of a wanted person. Because community members are rarely eager for this interaction with a police officer, these situations can be volatile and result in physical altercations and/or use of force incidents (La Vigne et al. 2014). This is particularly relevant in Milwaukee, given the tense police-community relationships that were exacerbated by the shooting of Dontre Hamilton.

Furthermore, subjects stop are highly discretionary activities, as the burden of proof to conduct this type of stop is very low (i.e., reasonable suspicion) and are often based on the officer's interpretation of the individual's behaviors. Many agencies across the country have faced community and federal criticism because of the low evidentiary threshold required for such activities (White and Fradella 2016). As such, the results of this study may also be due to BWC-equipped officers wanting to avoid highly discretionary, low-burden-of-proof activities that can now be reviewed both internally by supervisors and publically if the video is released.

Conversely, park and walks often involve officers walking around neighborhoods or business developments and having friendly interactions with community members, business owners and employees, etc. In general, these activities serve a community policing function and are unlikely to result in confrontation or in the use of force. Thus, these findings suggest that officers are becoming more hesitant after receiving body cameras to engage in activities that may result in negative interactions with the public, and are potentially replacing these with activities that are more positive or communityoriented.

It is worth noting that traffic stops, which also have the potential to result in confrontations between officers and community members, did not decrease significantly in most of our models. This may be because traffic stops are seen as a core responsibility of police officers and are often initiated using more tangible justifications than subject stops (e.g., a broken taillight or expired tags versus a person acting suspiciously). As such, officers may feel more comfortable engaging in these activities while wearing a body camera than in subject stops. In addition, most of the patrol cars in Milwaukee were already equipped with dash cameras. Thus, police-community interactions during traffic stops were already being recorded before BWCs were introduced, which may explain why these did not change significantly after BWCs were deployed.

Finally, this study offered a first-of-its-kind examination into RCT contamination and the degree to which being on scene with an individual assigned to the other experimental group altered officer behaviors. In all models, contamination levels 
were significantly, positively associated with the number of proactive activities that were conducted; however, the size of this effect was very small, ranging from an increase of 0.19 to $1.06 \%$ across the outcomes for each $1 \%$ increase of contamination levels. One might hypothesize that these findings are because the increased chances of being present at an event with contamination as officers conduct more activities in general. However, while the relationships are positive, the correlation between the number of activities and the percent of events that were contaminated produced very weak Pearson's $r$ coefficients (proactive activities: $r=.03, p<.01$; traffic stops: $r=.04, p<.001$; business checks: $r=.11, p<.001$; subject stops: $r=$ $.08, p<.001$; park and walks: $r=.15, p<.001)$. Future research should continue to explore ways to measure contamination and assess the degree to which it affects RCTs of BWCs.

\section{Limitations and conclusion}

A number of limitations in this study present opportunities for future research on BWCs. First, because the results of this study are limited to experiences from a single, large jurisdiction, our findings have limited generalizability. Of the estimated $47 \%$ of the law enforcement agencies that have deployed BWCs (Hyland 2018), few have done so in the same environment or by the same process as the MPD. For example, the MPD deployed BWCs after a highly public officerinvolved shooting and in the midst of calls for action from the community and city officials. In response, the MPD quickly developed a BWC policy and then deployed cameras to all eligible officers in the department (approximately 1100) within a 15-month period. This is a substantially quicker timeline than has been attempted by most other large agencies. Moreover, the MPD deployed BWCs to other officers prior to and during the RCT study period, while all control group officers received BWCs at the end of the study period. Combined, the rapid adoption of BWCs in the city, high amounts of public scrutiny, and phased rollout of cameras may have factored into our findings. Officers selected for the RCT may have begun altering their behaviors prior to being equipped with a BWC and were likely influenced by the behaviors of officers not involved in the RCT. Thus, the changes we observed in our study, particularly around the reduction in subject stops, may not be generalizable to other agencies.

Second, there are likely many other factors that contribute to why officers choose to engage in a specific policing activity. The number of prior complaints against an officer, the number of an officer's prior use of force incidents, an officer's attitudes toward BWCs, and the attitudes of an officer's immediate supervisor, among others, may all influence how an officer behaves when equipped with a body camera and can provide new research avenues that this study could not explore.

Further, though our study was focused on officer-initiated activities, our outcome measures were somewhat limited. We examined proactive activities at the officer-event level, which means that we identified all officers on scene at an event regardless of whether they were the ones to actually initiate the event or arrived on scene later as backup. For that reason, our findings indicate that sergeants were substantially more 
likely to have been involved in traffic and subject stops, even though it is unlikely that they initiated more of these stops than the patrol officers. While this method was critical for understanding the full picture of proactive activities, and particularly for measuring contamination at these events, it obfuscates the direct impact of BWCs on self-initiated activities. Future research should examine separate events that the officer directly initiated versus the events that they were involved in as a secondary responder, but were initiated by another officer.

Finally, this study was based on an intent-to-treat evaluation model and we were unable to corroborate whether the officers wore their BWCs as required, the degree to which they used their BWCs during the proactive activities, and whether they actively informed community members that their interactions were being recorded. While we could not systematically document these factors, the researchers conducted interviews and rode along with MPD officers and supervisors during the study period. The vast majority of officers reported favorable opinions of the BWCs and indicated that they used them as required. Likewise, the supervisor in charge of the BWC program occasionally reviewed officer footage and reported relatively high levels of compliance with the department's BWC policy. In most cases of noncompliance, officers simply forgot to turn on the camera or were in a situation where it was not safe or practical to do so. Further, it is very unlikely that officers assigned a BWC did not wear it, as the RCT was implemented in the middle of a department-wide effort with significant public interest and oversight. Still, potential concerns about endogeneity remain as BWC activation decisions, rather than merely being equipped with a camera, may be a stronger indicator of these proactive activities.

Relatedly, a study by Lawrence et al. (2019) notes that BWC use - as measured by activations - varied widely across officers, over time, and by policing activity. This is particularly relevant for a study of proactivity, as some of these activities are less likely to be recorded than others. For example, in the current study, it is unclear how often officers would have activated their cameras during activities like park and walks. Per the department's policy, MPD officers were required to record nearly every contact with community members. Unlike traffic and subject stops, though, park and walks do not always result in contact with community members and may instead involve officers walking around a particular area to provide a police presence. Thus, it is possible that officers chose to engage in more activities that did not require them to activate their cameras. However, questions about activation rates for proactive activities are outside the scope of this paper, which focuses on the amount of activities as opposed to the behaviors and outcomes of those activities. Future research should examine the degree that BWCs are activated during proactive activities and how their use affects these events.

The purpose of this study was to assess how BWCs influence police officers' decisions to initiate proactive activities. Results indicate that while the total amount of proactive activities remains unchanged, BWC-equipped officers tend to pursue activities that are less likely to result in a confrontation with community members or are highly discretionary with a low evidentiary threshold. As departments continue to develop BWC programs or fine-tune their existing BWC policies, more research is needed to understand the degree to which BWCs affect officers' behaviors and interactions with the public. 
Acknowledgments This project was supported by Grant No. 2015-WY-BX-0006 awarded by the Bureau of Justice Assistance. The Bureau of Justice Assistance is a component of the Department of Justice's Office of Justice Programs, which also includes the Bureau of Justice Statistics, the National Institute of Justice, the Office of Juvenile Justice and Delinquency Prevention, the Office for Victims of Crime, and the SMART Office. The opinions, findings, conclusions, and recommendations expressed here are those of the authors and should not be attributed to the U.S. Department of Justice, the Urban Institute, its trustees, or its funders. Funders do not determine research findings or the insights and recommendations of urban experts. Further information on the Urban Institute's funding principles is available at urban.org/fundingprinciples. We would like to thank staff from the Milwaukee Police Department, especially Sgt. Doug Wiorek, who played a significant role in working with the researchers for this study and article.

Open Access This article is distributed under the terms of the Creative Commons Attribution 4.0 International License (http://creativecommons.org/licenses/by/4.0/), which permits unrestricted use, distribution, and reproduction in any medium, provided you give appropriate credit to the original author(s) and the source, provide a link to the Creative Commons license, and indicate if changes were made.

\section{References}

Ariel, B., Farrar, W. A., \& Sutherland, A. (2015). The effect of police body-worn cameras on use of force and citizens' complaints against the police: a randomized controlled trial. Journal of Quantitative Criminology, 31(3), 509-535.

Ariel, B., Sutherland, A., Henstock, D., Young, J., Drover, P., Sykes, J., Megicks, S., \& Henderson, R. (2016a). Wearing body cameras increases assaults against officers and does not reduce police use of force: results from a global multi-site experiment. European Journal of Criminology, 13(6), 744-755.

Ariel, B., Sutherland, A., Henstock, D., Young, J., Drover, P., Sykes, J., Megicks, S., \& Henderson, R. (2016b). Report: increases in police use of force in the presence of body-worn cameras are driven by officer discretion: a protocol-based subgroup analysis of ten randomized experiments. Journal of Experimental Criminology, 12(3), 453-463.

Ariel, B., Sutherland, A., \& Sherman, L. W. (2018). Preventing treatment spillover contamination in criminological field experiments: the case of body-worn police cameras. Journal of Experimental Criminology.

Bertrand, M., Duflo, E., \& Mullainathan, S. (2004). How much should we trust difference-in-differences estimates? Quarterly Journal of Economics, 119(1), 249-275.

Brackens, K., \& Steffick, S. (2017). Violence reduction network: VRN 2016 annual report. Final report to the Bureau of Justice Assistance, 2015-DG-BX-K001. Accessed on August 15, 2019. Retrieved from https://www.nationalpublicsafetypartnership.org/ItemsOfInterest/AnnualReport2016/\#TopMain.

Braga, A., Coldren, J. R., Sousa, W., Rodriguez, D., \& Alper, O. (2017). The benefits of body-worn cameras: new findings from a randomized controlled trial at the Las Vegas Metropolitan Police Department. Final report to the National Institute of Justice, 2013-IJCX-0016. Washington, DC: CNA.

Braga, A. A., Sousa, W. H., Coldren Jr., J. R., \& Rodriguez, D. (2018). The effects of body-worn cameras on police activity and police-citizen encounters. The Journal of Criminal Law and Criminology, 108(3), 511538.

Farrar, T., \& Ariel, B. (2013). Self-awareness to being watched and socially desirable behavior: a field experiment on the effect of body-worn cameras and police use of force. Washington, DC: Police Foundation.

Federal Bureau of Investigation (FBI) (2017). Uniform crime reports, Table 6, Wisconsin, offenses known to law enforcement by city, 2016. Accessed on June 19, 2019. Retrieve at https://ucr.fbi.gov/crime-in-the-u. s/2016/crime-in-the-u.s.-2016/tables/table-6/table-6-state-cuts/wisconsin.xls.

Grossmith, L., Owens, C., Finn, W., Mann, D., Davies, T., \& Baika, L. (2015). Police, camera, evidence: London's cluster randomised controlled trial of body worn video. London, England: College of Policing Limited and the Mayor's Office for Policing and Crime.

Headley, A. M., Guerette, R. T., \& Shariati, A. (2017). A field experiment of the impact of body-worn cameras (BWCs) on police officer behavior and perceptions. Journal of Criminal Justice, 53, 102-109.

Hedberg, E. C., Katz, C. M., \& Choate, D. E. (2016). Body-worn cameras and citizen interactions with police officers: estimating plausible effects given varying compliance levels. Justice Quarterly, 34(4), 627-651.

Hilbe, J. M. (2011). Negative binomial regression. Cambridge: Cambridge University Press. 
Horner, S., Rew, L., \& Torres, R. (2006). Enhancing intervention fidelity: a means of strengthening study impact. Journal for Specialists in Pediatric Nursing, 11(2), 80-89.

Hyland, S. S. (2018). Body-worn cameras in law enforcement agencies, 2016. Washington, DC: Office of Justice Programs, Bureau of Justice Statistics.

Jennings, W. G., Fridell, L. A., \& Lynch, M. D. (2014). Cops and cameras: officer perceptions of the use of body-worn cameras in law enforcement. Journal of Criminal Justice, 42(6), 549-556.

Katz, C. M., Choate, D., Ready, J., \& Nuño, L. (2014). Evaluating the impact of officer worn body cameras in the Phoenix Police Department. Phoenix: Arizona State University, Center for Violence Prevention and Community Safety.

Katz, C. M., Kurtenbach, M., Choate, D. E., \& White, M. D. (2015). Phoenix, Arizona, smart policing initiative: evaluating the impact of police officer body-worn cameras. Washington, DC: Bureau of Justice Assistance.

La Vigne, N. G., Lachman, P., Rao, S., \& Matthews, A. (2014). Stop and frisk: balancing crime control with community relations. Washington, DC: The Urban Institute.

Lawrence, D. S., McClure, D., Malm, A., Lynch, M., \& La Vigne, N. G. (2019). Activation of body-worn cameras: variation by officer, over time, and by policing activity. Criminal Justice Review, 44(3), 339355.

Long, J. S., \& Freese, J. (2006). Regression models for categorical and limited dependent variables using Stata. College Station, TX: Stata Press.

Lum, C., Stoltz, M., Koper, C. S., \& Scherer, J. A. (2019). Research on body-worn cameras: What we know, what we need to know. Criminology \& Public Policy, 18(1), 93-118.

MacDonald, J. M., \& Lattimore, P. K. (2010). Count models in criminology. In A. R. Piquero \& D. Weisburd (Eds.), Handbook of quantitative criminology (pp. 683-698). New York: Springer.

Milwaukee Police Department (MPD). (2019). Standard Operating Procedure: 747 - Body worn cameras (BWC). Milwaukee, WI: Milwaukee Police Department.

Morrow, W. J., Katz, C. M., \& Choate, D. E. (2016). Assessing the impact of police body-worn cameras on arresting, prosecuting, and convicting suspects of intimate partner violence. Police Quarterly, 19(3), 303325.

Owens, C., Mann, D., \& McKenna, R. (2014). The Essex body worn video trial: The impact of body worn video on criminal justice outcomes of domestic abuse incidents. London, England: College of Policing.

Peterson, B. E., Yu, L., Vigne, N. L., \& Lawrence, D. S. (2018). The Milwaukee Police Department's bodyworn camera program: evaluation findings and key takeaways. Washington, DC: Urban Institute.

Piza, E. L. (2012). Using Poisson and negative binominal regression models to measure the influence of risk on crime incident counts. Newark, NJ: Rutgers University, Rutgers Center on Public Security.

Ready, J. T., \& Young, J. T. N. (2015). The impact of on-officer video cameras on police-citizen contacts: findings from a controlled experiment in Mesa, AZ. Journal of Experimental Criminology, 11(3), 445458.

Shjarback, J. A., Pyrooz, D. C., Wolfe, S. E., \& Decker, S. H. (2017). Depolicing and crime in the wake of Ferguson: racialized changes in the quantity and quality of policing among Missouri police departments. Journal of Criminal Justice, 50, 42-52.

U.S. Attorney's Office. (2019). Project Safe Neighborhoods (PSN): Eastern District of Wisconsin Strategic Plan. Accessed on August 15, 2019. Retrieved from https:/www.justice.gov/usao-edwi/project-safeneighborhoods.

U.S. Census Bureau (2016). 2012-2016 American Community Survey 5-year estimates. U.S. Census Bureau. Accessed on June 19, 2019 through the American FactFinder, available at https:/factfinder.census.gov.

Wallace, D., White, M. D., Gaub, J. E., \& Todak, N. (2018). Body-worn cameras as a potential source of depolicing: testing for camera-induced passivity. Criminology, 56(3), 481-509.

White, M. D., \& Fradella, H. F. (2016). Stop and frisk: the use and abuse of a controversial policing tactic. New York City: New York University Press.

White, M. D., Todak, N., \& Gaub, J. E. (2017). Assessing citizen perceptions of body-worn cameras after encounters with police. Policing: An International Journal, 40(4), 689-703.

White, M. D., Todak, N., \& Gaub, J. E. (2018). Examining body-worn camera integration and acceptance among police officers, citizens, and external stakeholders. Criminology \& Public Policy, 17(3), 649-677.

Young, J. T. N., \& Ready, J. T. (2018). A longitudinal analysis of the relationship between administrative policy, technological preferences, and body-worn camera activation among police officers. Policing: A Journal of Policy and Practice, 12(1), 27-42. 
Publisher's note Springer Nature remains neutral with regard to jurisdictional claims in published maps and institutional affiliations.

Daniel S. Lawrence, PhD in Criminology, Law, and Justice, is a senior research associate in the Justice Policy Center at the Urban Institute. His research interests include police technology, police legitimacy and procedural justice, police screening and hiring practices, and community policing. Dr. Lawrence received his $\mathrm{MA}$ and $\mathrm{PhD}$ from the University of Illinois at Chicago. He was a Co-Principal Investigator on this project.

Bryce E. Peterson, $\mathrm{PhD}$, is a principal research associate in the Justice Policy Center at the Urban Institute. His research focuses on correctional policy, children of justice-involved parents, prison population forecasting, and technological interventions in criminal justice settings. He was a Co-Principal Investigator on this project. 